corticoesteroids, malabsortive disorders, chronic systemic disorders such as nephropathies or hematologic diseases, etc. The patients or their legal tutors signed the Informed Consent in order to participate in the study. The average daily calcium intake was collected through the Spanish INDICAD 2001 study survey, together with a comprehensive anamnesis. If patients or their family reported taking food not included in the survey, its calcium content were consulted in the Spanish Food Composition Database published by the BEDCA Network of the Ministry of Health Science and Innovation

Results: Data were collected from 50 patients, with a mean age of 9.2 years (2-20), $28(56 \%)$ female, $86 \%$ Caucasian, 6\% Arab, 2\% Asian and $6 \%$ Latin. The most frequent diagnoses were: Food intolerances/malabsorption: $32 \%$, nephropathies: $22 \%$, JIA: $16 \%$, vasculitis: $10 \%$, other inflammatory diseases: $8 \% .42 \%$ had received systemic corticosteroids at some point, and $16 \%$ were receiving corticosteroids at present. Average daily calcium intake was $718 \mathrm{mg} / \mathrm{d}$. They were divided by age groups, attending to daily calcium needs per group. In Table 1 we can observe the Recommended Daily Amount (RDA) of calcium by the Spanish Association of Pediatrics and the consumption collected, by age group.

\begin{tabular}{lccccc}
\hline Age group & $\begin{array}{c}\% \text { Age } \\
\text { group }\end{array}$ & $\begin{array}{c}\text { RDA } \\
(\mathrm{mg} / \mathrm{d})\end{array}$ & $\begin{array}{c}\text { Average intake } \\
(\mathrm{mg} / \mathrm{d}) \pm \mathrm{SD}\end{array}$ & $\begin{array}{c}\text { Range: } \min -\max \\
(\mathrm{mg} / \mathrm{d})\end{array}$ & $\begin{array}{c}\% \text { That reaches } \\
\text { RDA }\end{array}$ \\
\hline Pre-escholar $(2-3 \mathrm{a})$ & $14 \%$ & 700 & $819 \pm 280$ & $513-1346$ & $57.1 \%$ \\
Escholar $(4-9 \mathrm{a})$ & $32 \%$ & 1000 & $702 \pm 240$ & $254-1075$ & $18.8 \%$ \\
Teenagers $(10-17 \mathrm{a})$ & $48 \%$ & 1300 & $689 \pm 350$ & $350-1925$ & $8.3 \%$ \\
Young (18-20 a) & $6 \%$ & 1100 & $797 \pm 182$ & $621-985$ & $0 \%$ \\
\hline
\end{tabular}

Only 3 children with low calcium intake were taking supplements.A decrease in calcium RDA adherence was observed with increasing age, statistically significant $(p=0.009)$. There was also a lower calcium intake in the non-Caucasians compared to Caucasians statistically significant $(p=0.044)$, which was not associated with age.

Conclusions: Calcium intake in the population under 21 years old with at least 1 risk factor for developing low bone mass/osteoporosis is lower than recommended. In addition, recommendations are based on the physiological needs of the healthy population and it could be expected to be insufficient for those with chronic diseases. It should be noted that calcium intake in the groups with higher requirements (adolescents and young people) is lower, with a reduction in the proportion of patients who meet the compliance with the RDA as age increases. Studies with a larger population are needed to ratify these results together with serum calcidiol levels

Disclosure of Interest: None declared

DOI: 10.1136/annrheumdis-2017-eular.2049

\section{AB0949 THE ANNUAL COST OF PATIENTS WITH JUVENILE IDIOPATHIC ARTHRITIS}

B. Serpen ${ }^{1}$, O. Altug-Gucenmez ${ }^{1}$, C. Acari ${ }^{1}$, M.K. Sozmen ${ }^{2}$, B. Makay ${ }^{1}$, S.E. Unsal ${ }^{1}$. ${ }^{1}$ Faculty of Medicine, Unit of Pediatric Rheumatology, Dokuz Eylul University; ${ }^{2}$ Faculty of Medicine, Department of Public Health, Izmir Katip Celebi University, Izmir, Turkey

Background: The management of juvenile idiopathic arthritis (JIA) includes various methods including such as medication, hospitalization, rehabilitation.

Objectives: To determine how much juvenile idiopathic arthritis cost; the components of this cost; how new treatments, i.e. biologics, improve the disease course and hospital expenditures.

Methods: This study was conducted in Dokuz Eylul University, Pediatric Rheumatology Unit between March 2015-March 2016. One-hundred six JIA patients who had a follow-up period of at least 1 year according to International Edmonton 2001 criteria were included. This retrospective cost study evaluated the data of these patients and calculated the direct cost for the follow-up period. Clinical data was collected from patient files that were in department's archive and cost data was gathered from Probel Hospital Information Management system. Patient data form covering sociodemographic and clinical information, patient drug form and annual medical cost form was filled out for each patient.

Results: $58.5 \%(n=62)$ of patients was female and $41.5 \%(n=44)$ was male. The mean age was $12.0 \pm 4.3$ years. $34.0 \%(n=36)$ of patients was oligoarticular type, $28.3 \%(n=30)$ was poliarticular type, $22.6 \%(n=24)$ was enthesitis related arthritis (ERA), 8,5\% ( $n=9)$ was psoriatic type and $6.6 \%(n=7)$ was systemic type. The cost of medication counted for $88.3 \%$ (453244.94 TL) of total direct annual cost. Total direct medical cost was highest for ERA ( $n=7742.55 \pm 9891 \mathrm{TL})$. While the annual cost was calculated as $10451 \mathrm{TL}$ per person for biologic using patients, for the patients using non-biologic treatments it was determined as 1472 TL per person. $1 \mathrm{TL}=0.32 € 1 \mathrm{TL}=0.35 \$$

Conclusions: Medication is responsible for most of the total direct medical cost in patients with JIA. Our results showed concordance with previous studies on the subject. This situation could be attributed to biologic agents that are being used in treatment in recent years. More prospective studies on the effectiveness of cost of treatment, with greater amount of patient and more homogenous subgroups are needed.

Disclosure of Interest: None declared

DOI: 10.1136/annrheumdis-2017-eular.5743

\section{AB0950 PREDICTORS OF RESPONSE TO ETANERCEPT TREATMENT DEPENDING ON JUVENILE IDIOPATHIC ARTHRITIS CATEGORY}

E. Kashchenko ${ }^{1}$, E. Alexeeva ${ }^{1,2}$, T. Bzarova ${ }^{1,2}$, S. Valieva ${ }^{1}$, R. Denisova ${ }^{1}$, O. Lomakina ${ }^{1}$, K. Isaeva $^{1}$, M. Soloshenko ${ }^{1}$, A. Karaseva ${ }^{1} .{ }^{1}$ Federal State Autonomous Institution "National Scientific and Practical Center of Children's Health" of the Ministry of Healthcare of the Russian Federation; ${ }^{2}$ I.M. Sechenov First Moscow State Medical University, Moscow, Russian Federation

Background: Anti-TNF biologics are highly effective and widely used in clinical practice for the treatment of JIA. However, some children lack of response with few reliable predictors of a good or poor response to treatment found [1-3]. As clinical picture patterns are significantly differ for $7 \mathrm{JIA}$ subclasses, we propose to found predictors of response to therapy for each of JIA category.

Objectives: To identify clinical and laboratory parameters associated with response to etanercept treatment in 12 months in patients with different JIA category.

Methods: Patients from four JIA categories $(n=195)$ were divided to groups with excellent, intermediate and poor response after 12 month treatment with etanercept according to ACRPedi criteria, achieving inactive disease by Wallace criteria and JADAS-71 cut-off point. For each of JIA category univariate and multivariate logistic regression analysis was conducted to identify potential baseline factors associated with treatment response. Baseline factors included clinical, laboratory and anamnestic data.

Results: From total cohort 91/90/85/68.5 percent of patients achieved ACR30/50/70/90 in one year etanercept treatment; $45.5 \%$ patients were considered excellent responders, $30 \%$ - intermediate responders, and $24.5 \%$ - poor responders. Highest efficacy of therapy was shown in persistent oligoarthritis patient, lowest - in enthesitis-related arthritis and polyarthritis patients. Potential baseline predictors of excellent and poor response which were significant are described in the table.

\begin{tabular}{lcc}
\hline JIA category & Predictors of excellent response & Predictors of poor response \\
\hline Persistent oligoarthritis & smaller amount of DMARD & - \\
Extended oligoarthritis & shorter disease duration (DD) & - \\
Enthesitis-related arthritis & - & - longer DD \\
RF-negative polyarthritis & $\begin{array}{c}\text { - smaller number of joints with limited } \\
\text { range of motion (LOM) }\end{array}$ & - longer DD \\
& - older ADO \\
& - lower CRP level at the baseline \\
& -younger age at disease onset (ADO)
\end{tabular}

Analysis showed that poor response in all JIA categories was mainly associated with demographic data (longer DD and older ADO). However, factors associated with excellent response significantly differed depending on JIA category (anamnestic factors, number of involved joints, laboratory factors, and demographic factors).

Conclusions: Response to etanercept therapy is strongly associated with JIA category. Shorter disease duration and lower number of DMARDs used before start of etanercept, lower number of joints with LOM, and lower C-reactive protein at baseline are predictors of better response to etanercept.

\section{References:}

[1] Otten MH, et al. JAMA 2011;306:2340-7.

[2] Kearsley-Fleet L, et al. Rheumatology (Oxford) 2016;55:840-7.

[3] Solari N, et al. J Rheumatol 2013;40:192-200.

Disclosure of Interest: E. Kashchenko Grant/research support from: Novartis, E. Alexeeva Grant/research support from: Roche, Abbott, Pfizer, Bristol-Myers Squibb, Centocor, Novartis, Speakers bureau: Roche, Merck Sharp \& Dohme, Abbott, Bristol-Myers Squibb, Medac, Novartis, Pfizer, T. Bzarova Grant/research support from: Roche, Pfizer, Novartis, Speakers bureau: Roche, Merck Sharp \& Dohme, Abbott, Pfizer, S. Valieva Grant/research support from: Roche, BristolMyers Squibb, Speakers bureau: Roche, Merck Sharp \& Dohme, Bristol-Myers Squibb, Medac, Novartis, R. Denisova Grant/research support from: Roche, Centocor, Novartis, Speakers bureau: Roche, Merck Sharp \& Dohme, Abbott, Medac, O. Lomakina: None declared, K. Isaeva Grant/research support from: Roche, Novartis, M. Soloshenko: None declared, A. Karaseva: None declared DOI: 10.1136/annrheumdis-2017-eular.3918

\section{AB0951 FACTORS ASSOCIATED WITH RESPONSE TO ADALIMUMAB TREATMENT IN JUVENILE IDIOPATHIC ARTHRITIS}

E. Kashchenko ${ }^{1}$, E. Alexeeva ${ }^{1,2}$, T. Bzarova $^{1,2}$, S. Valieva ${ }^{1}$, R. Denisova ${ }^{1}$, O. Lomakina ${ }^{1}$, K. Isaeva ${ }^{1}$, M. Soloshenko ${ }^{1}$, A. Karaseva ${ }^{1} .{ }^{1}$ Federal State Autonomous Institution "National Scientific and Practical Center of Children's Health" of the Ministry of Healthcare of the Russian Federation; ${ }^{2}$ I.M. Sechenov First Moscow State Medical University, Moscow, Russian Federation

Background: Tumor necrosis factor inhibitors are highly effective and safe in treatment of juvenile idiopathic arthritis (JIA). Nonetheless, to select the optimal therapy and to achieve maximum therapeutic effect it is necessary to consider the individual characteristics of the patient. Adalimumab (ADA) is widespread use for mild and severe polyarticular JIA especially in the presence of uveitis, but there is lack of data about clinical and laboratory predictors of response to ADA in different JIA categories.

Objectives: To identify clinical and laboratory parameters associated with 